\title{
3- A MATERIALIDADE DO QUE SOMOS
}

Josemar da Silva Martins

$(\text { Pinzoh })^{1}$

\section{Resumo}

Este ensaio é construído sobre bases empíricas não disciplinadas em uma pesquisa específica, mas, se apoia em dados da realidade social recolhidos e registrados em oportunidades distintas e com uso de instrumentos diversos, que vão desde a anotação episódica, à fotografia, ao audiovisual, ao depoimento espontâneo e ao murmúrio pessoal solitário, sendo parte de um esforço de constituição de uma reflexão frente às imagens que as cidades que habitamos nos oferecem, através de uma conduta mais próxima da figura do flâneur e da atitude de flânerie, ou até mais interessado que tais figuras. Tomo particularmente as cidades de Juazeiro e Curaçá, no norte baiano, a partir das quais problematizo um conjunto de circunstâncias da vida cotidiana, destacando alguns aspectos da vida social - como as festas, a arborização urbana, o lixo - aspectos a partir dos quais é possível problematizar o que somos para além das abordagens baseadas no conceito de "representações sociais" (ANADON; MACHADO, 2001) ou de "discurso" (FOUCAULT, 1999), mas tomando como base a materialidade dos nossos modos der ser plasmados nas feições das cidades. Neste caso, a discussão é conduzida para o terreno da ecologia - ou mais precisamente da ecosofia (GUATTARI, 1990).

Palavras Chaves: Representações Sociais, Estrutura Urbana, Ecologia Humana, Ecosofia.

\section{Summary}

This essay is built on empirical bases not subject to specific research, but is based on social reality data collected and recorded in different opportunities and using different instruments, ranging from episodic annotation, photography, audiovisual, spontaneous testimony and to the solitary personal murmur, being part of an effort to constitute a reflection in front of the images that the cities that we inhabit offer us, through a conduct closer to the figure of the flâneur and the attitude of flânerie, or even more interested than such figures. I am particularly concerned with the cities of Juazeiro and Curaçá, in northern Bahia, from which I problematize a set of everyday life circumstances, highlighting some aspects of social life - such as festivals, urban afforestation, garbage - aspects from which It is possible to problematize what we are in addition to the approaches based on the concept of "social representations" (ANADON; MACHADO, 2001) or "discourse" (FOUCAULT, 1999), but based on the materiality of our ways of being embodied in the cities. In this case, the discussion is conducted on the terrain of ecology - or more precisely on ecosophy (GUATTARI, 1990).

Keywords: Social Representations, Urban Structure, Human Ecology, Ecosophy.

\footnotetext{
${ }^{1}$ Professor Adjunto da UNEB no DCH III e docente do Programa de Pós-Graduação Mestrado em Educação, Cultura e Territórios Semiáridos - PPGESA.
} 


\section{Resumen}

Este ensayo se construye sobre bases empíricas no disciplinadas en una investigación específica, pero se apoya en datos de la realidad social recogidos y registrados en oportunidades distintas y con uso de instrumentos diversos, que van desde la anotación episódica, a la fotografía, al audiovisual, al cine, el testimonio espontáneo y el murmullo personal solitario, siendo parte de un esfuerzo de constitución de una reflexión frente a las imágenes que las ciudades que habitamos nos ofrecen, a través de una conducta más cercana a la figura del flâneur y de la actitud de flanerie, o incluso más interesado que tales figuras. Tomo particularmente las ciudades de Juazeiro y Curaçá, en el norte de Bahía, a partir de las cuales problematizo un conjunto de circunstancias de la vida cotidiana, destacando algunos aspectos de la vida social como las fiestas, la arborización urbana, la basura - aspectos a partir de los cuales es posible problematizar lo que somos más allá de los enfoques basados en el concepto de "representaciones sociales" (ANADON, MACHADO, 2001) o de "discurso" (FOUCAULT, 1999), pero tomando como base la materialidad de nuestros modos plasmados en las características de las ciudades. En este caso, la discusión se conduce hacia el terreno de la ecología - o más precisamente de la ecosofía (GUATTARI, 1990).

Palabras claves: Representaciones Sociales, Estructura Urbana, Ecología Humana, Ecosofía.

\section{O modus operandi}

O produtivismo acadêmico, atualmente em vigor, recomenda que priorizemos em nossas pesquisas e produções acadêmicas as referências publicadas nos últimos cinco anos, com destacada prioridade para aquelas que são publicações qualis. Declaro, desde já, meu desinteresse por essa mesquinharia de aprisionamento das formas de pensar e de fazer "ciência", demarcadas por um presenteísmo mal explicado que hoje predomina nos discursos sobre Ciência, Tecnologia e Inovação (CT\&I). Aliás, tal aspecto só me interessa como dado de uma realidade que necessita urgentemente de problematizações. De modo geral, tenho sérias dúvidas sobre se o capital do saber que hoje acumulamos nos trabalhos acadêmicos (TCCs, Dissertações, Teses, artigos), amparados pela chancela de "ciência", estão servindo pelo menos para qualificar um novo senso comum, como quer Boaventura Santos (2008), senão para arruiná-lo ainda mais, dada a quantidade de besteiras que os grupos de WhatsApp têm circulado, enviadas por alunos iniciantes e pelos doutos de nossas universidades. Ainda assim, é no terreno do trabalho acadêmico de pensamento e também sob a chancela da "ciência" que o presente texto se expressa. No entanto, sem nenhum interesse em reiterar formas 
engessadas, tão em vigor no lastro de nossas atuais experiências acadêmicas e científicas, priorizo aqui uma base teórica que, para além do princípio de novidade, apresenta questões que ainda considero importantes de serem retomadas para ampararem reflexões sobre a dimensão ontológica da vida.

Posto esse posicionamento, advirto para o fato deste texto estar mais para o gênero ensaio do que para o artigo científico, amparado por um rigor-outro. O que me exige que explique que, em termos metodológicos, este ensaio é construído sobre bases empíricas não disciplinadas em uma pesquisa específica - ou, dizendo de modo mais específico, equivale a uma pesquisa de todos os dias e lustros e anos. Vivendo no mundo, aqui neste chão de sertão, na fronteira de um tempo obtuso, não sou apenas o flâneur - entendido como tradução do espírito de mobilidade que se inaugura com a modernidade (ORTIZ, 2000), figura desenraizada que se locomove através do espaço urbano remodelado e nele se desloca com sua conduta de contemplação, deslizando (flanando, surfando) entre a paisagem urbana. No entanto, não sendo apenas essa figura, a atitude que adoto ainda permanece próxima de um flâneur, mas um que não apenas passeia e passa, mas olha, se distancia, anota e reflete.

Segundo Ortiz (2000), Walter Benjamin agrega à figura do flâneur, a figura de uma atitude/atividade que paira entre trabalho e ócio, e que recupera o flâneur de uma mera deambulação. Ele nomeia essa atitude como flânerie, que pressupõe a ideia de distanciamento, a separação do que está sendo observado e ainda um conhecimento histórico, arqueológico que lhe conduz o interesse. Para Ortiz (op.cit.) a flânerie é uma atividade intelectual, uma arte, que reforça sua aproximação com o trabalho intelectual homóloga à da produção do conhecimento científico. Como ele mesmo diz (ORTIZ, 2000, p. 25), "seria tentador interpretar a arte da flânerie como uma espécie de crítica à mercantilização do conhecimento", por situar-se entre o interesse de trabalho e o desinteresse da deambulação. A diferença é que, enquanto Walter Benjamin estabelece a figura do flâneur dentro de um quadro positivo de entusiasmo em relação aos glamour da cidade de Paris da Belle Époque - o que implica em considerar o clima intelectual e artístico que isso congrega - a minha postura, ao contrário, implica em levar em conta o quadro de problemáticas do urbano caótico e sem glamour de nossas cidades. As imagens que testemunhamos estão distantes desse glamour e desse clima intelectual e artístico que compõem o investimento na constituição de um urbano cosmopolita e glamoroso, como o de Paris do século XIX. Pelo contrário, o urbano que desponta entre nós, embora embalado pelas transformações advindas de mudanças sociais e 
econômicas recentes, com visível impacto dos fluxos globais, expõe as vitrines e os paredões do "novos ricos", mas, igualmente, expõe a pobreza de imaginação e o precário clima intelectual e artístico.

Em todo caso, em termos metodológicos, o trabalho que empreendo aqui, decorre da experiência de andar atento - único elo com o flâneur de Benjamin (2009) e, portanto, se apoia em dados da realidade social recolhidos e registrados em oportunidades distintas de "passagens" em que, com uso de instrumentos diversos, que vão desde a anotação episódica, à fotografia, ao audiovisual, ao depoimento espontâneo e ao murmúrio pessoal solitário, constituem um esforço de reflexão frente às imagens que as cidades que habitamos nos oferecem. Nesse sentido, estamos também transitando nos campos de estudos em Cultura Visual (HERNÁNDEZ, 2007) e Antropologia Visual (FERRAZ; MENDONÇA, 2014).

Sendo natural da cidade de Curaçá, no norte do Estado da Bahia, cidade situada à margem direita do Rio São Francisco, a mais ou menos 600 km da cidade de Salvador, moro por 26 anos na cidade de Juazeiro, também no norte do Estado da Bahia, e igualmente situada à margem direita do Rio São Francisco, a 90 km de Curaçá e a 510 $\mathrm{km}$ da cidade de Salvador. A partir dessas duas cidades, dentro da experiência de pedagogo e professor-pesquisador da UNEB, Departamento de Ciência Humanas do campus III (DCH III), tenho percorrido caminhos - a trabalho e/ou a passeio - que nos levam a, e/ou cruzam outras cidades, mais próximas ou mais distantes, na Bahia ou nos estados vizinhos (Pernambuco, Piauí, Sergipe, Alagoas, Paraíba, Ceará...), atento às feições das configurações urbanas. De modo que o que aqui exponho é fruto dessas "passagens atentas" e do registro episódico das marcas dessas feições urbanas. Tais registros desse olhar são geralmente submetidos a aportes conceituais diversos que amparam as reflexões que aqui se mostram. Se há algo a dizer sobre o método de trabalho que ampara este ensaio, é isto.

\section{As bases conceituais}

Há diversas formas de encarar e problematizar o que somos, mas três delas me ocupam a reflexão neste momento: a) o que dizem os outros sobre nós; b) o que dizemos nós mesmos sobre nós; e c) o que diz de nós a materialidade da nossa vida cotidiana. No primeiro e no segundo casos, estamos lidando com os conceitos de representação social e de discurso - levando em conta que as representações sociais são 
sempre reverberadas, reiteradas e repercutidas no plano dos discursos. No terceiro caso, estamos em outro plano, cujos traços ainda estamos compondo.

Em relação ao conceito de representação social (relativa aos dois primeiros casos) é preciso que a situemos. Sua origem é a psicologia social europeia desde Durkheim, para o qual "o termo representação social se refere a representações coletivas, como uma forma de ideação social à qual se opõe a representação individual" (ANADON; MACHADO, 2001, p. 10), mas que termina por constituir as próprias ideações individuais, exatamente porque constitui os diversos tipos de produções mentais sociais que passam pelos campos da ciência, da religião, da ideologia, dos mitos e outros (Ibidem). Os diversos saberes, discursos e práticas acabam por arranjar um determinado quadro social de entendimento partilhado, que ampara a própria sociabilidade ordinária. No interior disso, o jogo duplo das representações sociais inclui aquilo que dizem sobre nós e aquilo que dizemos de nós mesmos, como um par que dança.

Para Anadon e Machado (2001, p. 13) as representações sociais não podem ser confundidas com sistemas teóricos mais elaborados, com teorias científicas, com as ideologias mais específicas ou com as imagens concebidas como produto da percepção, sendo um conceito que designa uma forma de conhecimento peculiar, como um saber do senso comum, estandardizado, embora misture contribuições e fragmentos não controlados dos sistemas teóricos científicos, das ideologias e, ultimamente, dos discursos das mídias e, por outro lado, retroativamente, tais representações também atravessam o plano da produção de saber especializado desses campos diversos, pelo fato de operar, em algum nível, uma espécie de condicionamento social do pensamento.

Segundo Sêga (2000) o conceito de representações sociais deriva da sociologia de Émile Durkheim e andava esquecido, até ser resgatado por Serge Moscovici, em 1961. De lá pra cá passou a ter uso frequente em trabalhos acadêmicos a na pesquisa de diversos campos do saber, nas ciências sociais e humanas. Talvez de um modo ainda não mapeado na teoria, as representações sociais constituam também aquilo que Teilhard de Chardin (2001) chamou de Noosfera e que Edgard Morin (1991) reforçou em $O$ Método $I V$, ao discutir a ecologia das ideias e o modo como elas operam as ações e a constituição do humano. Seria uma antroposfera, uma esfera da vida constituída pelo universo do pensamento humano, pela atividade mental, consciente ou não.

Assim construímos explicações sobre o que somos: baianos, nordestinos, curaçaenses, juazeirenses, homens, mulheres, gays, pretos, brancos, índios, bons, maus, 
honestos. Na maioria das vezes, para nos defendermos de uma representação que nos ofende (o que se diz, de fora, sobre nordestinos, por exemplo), organizamos uma representação compensatória (de dentro, como o "orgulho de ser nordestino"). Durval Muniz Albuquerque Júnior fez, por exemplo, em “A Invenção do Nordeste e Outras Artes" (1999) uma caprichosa discussão das configurações da produção histórica do imaginário social sobre ser nordestino, ou seja, sobre a construção discursiva, representacional e subjetiva de uma cartografia sentimental do Nordeste e do nordestino.

Neste ensaio, não pretendo aprofundar conceitos, nem os de representação social nem o de discurso, nem aqueles específicos sobre a construção discursiva do/sobre o Nordeste. Tais referencias são apenas retalhos de um panorama de possibilidades interpretativas, cujo aprofundamento o leitor deve buscar nos diversos textos dedicados a isso, aqui mesmo devidamente indicados. Interessa-me apenas, a partir desse panorama conceitual, problematizar duas coisas: o modo como construímos - na dinâmica entre o que os outros dizem de nós e aquilo que nós mesmos dizemos de nós uma cartografia sentimental e existencial para habitarmos nossas cidades, mesmo que, paradoxalmente, sequer sejamos coerentes com o que dizemos de nós mesmos e menos ainda notamos que vivemos presos a formas de vida que parecem dominadas por uma espécie de espírito de bando, como animais gregários, transitando entre o espírito de rebanho em Nietzsche e o homem de massas em Arendt (KUSKOSKI, 2011; NIETZSCHE, 2005; ARENDT, 2000).

De um modo ou de outro, é neste terreno onde busco a possibilidade de problematizar nossas condutas ordinárias, plasmadas no corpo das cidades, na feição se sua superfície pública, olhando primeiro o que fazemos, e buscando, em segundo lugar, questionar que ideias que amparam tais condutas. Neste caso, a despeito de todas essas contribuições teóricas, opto por olhar a realidade fisionômica e fenomênica das nossas cidades como expressão de uma ecosofia, que, segundo o criador do conceito, Félix Guattari (1990), integra três tipos de registros ecológicos: o do meio ambiente, o das relações sociais (o socius) e o da subjetividade humana (o modo como cada um/a singulariza os estímulos e adversidades socioambientais do meio). 


\section{A realidade observada: as formas de iniquidades}

Partindo da cidade de Juazeiro ou de Curaçá, em qualquer direção, vamos encontrar muitas outras cidades do sertão semiárido nordestino, na Bahia ou nos estados vizinhos. Eu as observo, quando chego e saio, quando paro, demoro ou não, pernoito, trabalho, passeio, ou simplesmente passo, vejo e penso. Em Curaçá tenho casa, família, amigos. Em Juazeiro, tenho casa, família, amigos e trabalho. Ando munido de blocos de anotações, canetas, máquina fotográfica, filmadora, celular... Olho, vejo, sinto cheiros (odores), vou a festas, reparo na paisagem. Aqui, não pratico ainda o trabalho de sair da imagem de capa, da superfície. Pelo contrário, a superfície me interessa, a feição, a rostidade urbana. Se em algum momento entro no detalhe - no banheiro da festa, pelas pontas dos pés para não ficar atolado na urina que já formou uma mancha lamacenta a cinco metros do vaso sanitário - também me interessa a imagem graúda da cidade, em bloco. Se, por um lado, também convivo com as distâncias de singularização (GUATTARI, 1990) de sujeitos que, apesar dos modos hegemônicos estabelecem outras relações estéticas e políticas (em Curaçá, por exemplo, a professora Rosana construiu uma casa ecológica, com tijolão orgânico, com fossa ecológica integrada à plantação de bananeiras; também lá um grupo de pessoas se juntam para plantar espécies de árvores nativas e outras na beira do rio e se unem para regar e limpar a orla da cidade), por outro lado, o traçado urbano caótico, as praças áridas, sujas e barulhentas, as árvores da urbanização urbana, as músicas que reverberam em alto volume nos bares, paredões sonoros e porta-malas dos carros, o lixo que se acumula como uma espécie de decoração bizarra que infesta todos os lugares...todas essas coisas me interessam no conjunto da problematização.

Interesso-me por aquilo que não pode ser disfarçado, porque é vista pública, concreta. Se no plano das explicações que organizamos sobre nós (no jogo duplo entre aquilo que dizem sobre nós e aquilo que dizemos de nós mesmos), estamos no terreno dos discursos e das representações sociais, no caso dessa imagem das cidades, em que terreno estamos? Como encarar a feição física e pública dos espaços que habitamos como excedente concreto daquilo que somos? Em que terreno conceitual "encaixotar" essa abordagem?

Há mais de 13 anos iniciei uma tematização dessas questões num seminário da cidade de Pintadas (BA), quando da abertura do Fórum de Cultural Regional, ocorrido dentro da programação da III Semana Cultural de Pintadas, em 2 de maio de 2004 - em 
que os participantes do fórum cunharam o termo "cultura amassada", fazendo alusão à noção de "cultura de massa" e a de uma coisa estragada (amassada). Naquele mesmo ano, em 17 de agosto, numa outra oportunidade, desta vez numa palestra no Seminário Permanente com Pesquisadores da Educação realizado pela Fundação Clemente Mariani em Salvador (BA), pudemos estabelecer a diferença entre a abordagem ecológica tradicional, pressa ao critério das interações "naturais" - que fundou o conjunto de tratados e a ordem ambiental internacional (RIBEIRO, 2001) - e a necessidade de estabelecer uma abordagem mais próxima da ecologia humana (EUFRASIO, 1999) e da ecosofia (GUATTARI, 1990).

No ano de 2008 fiz uma comunicação no I EBECULT (I Encontro Baiano de Estudos em Cultura), ocorrido na Faculdade de Educação da UFBA, em Salvador (BA), nos dias 11 e 12 de dezembro. Aqui discuti uma coisa que nomeei como "cultura da ‘fuleragem"”, em decorrência de um vídeo que fizemos em parceria com o dramaturgo Luiz Sérgio Ramos, chamado O Estado da Arte da Fuleragem ${ }^{2}$. No ano seguinte, 2009, no II EBECULT, ocorrido entre 20 e 21 de agosto na Universidade Estadual de Feira de Santana (UEFS), fiz uma comunicação na Mesa 31 (Cultura, cidade e paisagem), ampliando a abordagem para contemplar um panorama mais amplo da paisagem urbana. Ali, abordei as três formas de iniquidade estética na cultura contemporânea: lixo, fícus e fuleiragem. O presente ensaio é uma forma de dar prosseguimento a essas problematizações (que não foram pacificamente recebidas, porque talvez vigore $\mathrm{o}$ discurso de que "não podemos malhar nada", como disse Paulinho Boca de Cantor em O Estado da Arte da Fuleragem). No entanto, estabeleci uma conduta persistente no registro de tais aspectos em todas cidades em que vou ou passo. Recentemente, além do lixo, do fícus e da fuleiragem, a própria estrutura urbana vem sendo digna de anotação. Tais aspectos eu passo a expor, conforme segue.

\section{A. Estrutura urbana}

Darcy Ribeiro (1995), em O Povo Brasileiro, dedica uma parte do seu texto a discutir a urbanização caótica, ainda ali, tomada como parte de um crescimento desigual e excludente, expropriador, que marcou a constituição do Brasil desde seus primórdios e que nessas bases fez incharem as cidades, sem qualquer senso de planejamento. Bem

\footnotetext{
${ }^{2}$ 35’28 mim. Disponível no YouTube no endereço 〈https://youtu.be/U14Kfv6BUIM〉.
} 
antes dele, porém, numa obra cuja primeira edição é de 1936, Sérgio Buarque de Holanda, em Raízes do Brasil (HOLANDA, 1995), dedica um dos seus capítulos, que nomeia como "O Semeador e o Ladrilhador", para discutir as diferenças civilizatórias (e coloniais) entre os países da América Latina colonizados pela Espanha e o Brasil, colonizado por Portugal. A tese dele é a de que a Espanha foi mais prodigiosa em usar régua e compasso do que Portugal, que manteve-se quase que exclusivamente numa conduta de expropriação primária e caótica. Diferente dos espanhóis, diz ele,

\footnotetext{
A cidade que os portugueses construíram na América não é produto mental, não chega a contradizer o quadro na natureza, e sua silhueta se enlaça na linha da paisagem. Nenhum rigor, nenhum método, nenhuma previdência, sempre esse significativo abandono que exprime a palavra 'desleixo'..." (HOLANDA, 1995, p. 110).
}

Ora, tanto tempo depois, percebe-se que as cidades, sobretudo as do interior, as do sertão nordestino, pelo menos nos últimos 15 anos, passaram por um crescimento significativo, com a chegada de diversos empreendimentos comerciais e de serviços, que se expressa no número de veículos (carros, motos), de bares, lanchonetes, restaurantes, farmácias, postos de gasolina, borracharias, hotéis e pousadas, casas de material de construção... Vê-se, ao chegar e passar por elas, que há uma grande quantidade não só de empreendimentos, mas de residências novas, tetos novos, bairros novos, inclusive com construções luxuosas e até condomínios privados, mesmo nas cidades pequenas. Os novos bairros não são favelas que se ampliam, mas áreas residenciais semi-urbanizadas. O que não se observa, no entanto, é o mínimo planejamento público do urbano. Os negócios, as práticas comerciais (incluindo a especulação imobiliária) define o traçado do urbano.

Sobre este aspecto atual da vida nas nos sertões (incluindo suas cidades), Marcel Bursztyn, em reedição do livro O Poder dos Donos (BURSZTYN, 2008), vinte anos depois, estabeleceu uma atualização em forma de prólogo ("Prólogo a esta edição - $(\mathrm{Re})$ encontrando o sertão", p. 21-27) no qual fala das novidades, permanências e recorrências dos sertões, dando destaque à ampliação do urbano e às novas contradições que se instalam. O fato é que as cidades crescem repetindo os mesmos aspectos apontador por Holanda no início do século XX, por Ribeiro no final do século $\mathrm{XX}$, e por Bursztyn no início do século XXI: "sempre esse significativo abandono que exprime a palavra 'desleixo"' (HOLANDA, op. cit.).

$\mathrm{Na}$ maioria de nossas cidades não ouve falar de um plano diretor e do estabelecimento de uma postura pública mínima. Os negócios vão definindo o traçado 
urbano, vão invadindo, ocupando, se apropriando dos espaços e praças públicas ao seu bel prazer. Em Juazeiro, além de outros muitos eventos, o evento recente é a ocupação da "beira do rio", na área chamada Orla Nova (antes espaço da antiga Franave), por empreendedores de aluguel de caiaques, desenvolvendo um hábito novo de recreação nas águas do Rio São Francisco, mas, não se observa nenhum disciplinamento da atividade, tampouco o desenvolvimento de uma conduta de cuidado e preocupação com o rio, que está cada vez mais exaurido, atingindo, em 20117, a mais baixa vasão desde a construção da barragem da Usina Hidroelétrica de Sobradinho (colocada em operação em 1979), atingindo hoje míseros 550 metros cúbicos por segundo. Outro dado são os bairros dos residenciais do Programa Minha Casa Minha Vida, onde se percebe uma rápida depreciação do espaço habitado (lixo, arborização, destruição de equipamentos públicos).

Em Curaçá, a principal praça, a praça da rodoviária ou Praça Inácio Pereira Lima, é circundada de empreendimentos comerciais, além de bares que ficam na própria praça (acompanhando uma tendência de nossas cidades de terem sempre bares nos centros das praças), e todos eles usufruem da praça, porém, não lhe devolvem a mínima dignidade - pelo contrário, despejam nela os dejetos de suas atividades comerciais.

\section{B. Lixo}

O lixo tornou-se uma espécie de estética predominante, uma coisa quase "natural" e somos saudados à entrada das cidades pela quantidade de lixo que há em suas bordas, por um lixão fumegante à beira da entrada de acesso à cidade, e pelos papéis plásticos esvoaçantes se esfrangalhando pelas ramagens e arbustos. Em cidades como Quijingue (BA) ou São Raimundo Nonato (PI) é possível encontrar urubus nas ruas, no chão ou encimando postes, disputando as porcarias com cachorros e mendigos, bebendo água dos esgotos. E tanto as pessoas quanto os urubus parecem já terem se acostumado uns com os outros. Em Curaçá e em Juazeiro (e em todas as outras cidades), o fim das festas públicas e privadas, sem distinção, expõe a cara de nossa civilidade, a camada de lixo nos remete a uma imagem escatológica. Durante vários anos seguidos registro, por exemplo, a Festa de Vaqueiros de Curaçá, que ocorre todos os anos há 64 anos, no primeiro final de semana do mês de julho e que, recentemente, foi transformada em Patrimônio Cultural Imaterial da Bahia através da Lei Estadual $\mathrm{n}^{\circ}$ 13.691, de 11 de janeiro de 2017. Há mais ou menos oito anos registro esta festa e tenho 
reunido um conjunto formidável de fotografias e vídeos do lixo da festa. A Praça Inácio Pereira Lima, por exemplo, onde sempre ocorre atividades da festa e nos anos anteriores onde a festa se concentrou no último dia (com a exceção de 2017, em que houve uma alteração no formato), a festa é culminada com um tapete de lixo. Não se trata de lixo comum e barato. São pilhas de garras de whisky de marcas caras: Old Par, Ballantine's, Johnnie Walker, Chivas... As pessoas dançam por cima desse lixo, sem sequer pensarem na periculosidade de sua natureza. Além desse lixo de vidro, as latas de cerveja têm a vantagem de serem recolhidas por catadores de material reciclável. A imagem deixa claro que não se trata de uma pobreza material: a pobreza é de outra ordem!

Similar imagem se pode ver, por exemplo, na cidade de Juazeiro. Apesar de a cidade de Juazeiro hoje contar com um Aterro Controlado - diferente das outras cidades, que permanecem com lixões a céu aberto - e de haver a coleta regular de lixo, a cidade em si é extremamente suja. A imagem do lixo já não surpreende nem incomoda. Os habitantes da cidade já não se distanciam dela. A cidade possui um Mercado do Produtor, cujo poder municipal e a imprensa local afirmam ser o $4^{\circ}$ maior entreposto comercial do Brasil em volume de negócios. No entanto, é um dos lugares mais sujos da cidade, sendo este aspecto um motivo de reclamações e denuncias frequentes, que reverberam na imprensa local. Os terrenos baldios da cidade, de bairros centrais e até nobres, vivem sendo objeto de reclamações e até de ações na justiça, pelo acúmulo de lixo e tais locais.

A imagem mais formidável sobre isso que encontrei é a que consta no livro $A s$ cidades invisíveis, de Ítalo Calvino (1990), precisamente no conto "as cidades contínuas II”, no qual descreve a cidade de Leônia (p. 105- 107):

A cidade de Leônia se refaz a si própria todos os dias; sua população acorda todas as manhas num permanente estado de novidade: lençóis frescos, sabonetes recém-tirados da embalagem, roupões novíssimos, novas e avançadas geladeiras de onde saem latas ainda intatas, últimos modelos de rádio de onde se ouvem as últimas lengalengas. E para permanecer sempre tão nova, a Leônia de hoje joga fora todos os dias os restos da Leônia do dia anterior, envoltos em límpidos sacos plásticos: tubos retorcidos de pasta de dente, lâmpadas queimadas, jornais, recipientes, materiais de embalagem, aquecedores, enciclopédias, pianos, aparelhos de jantar de porcelana... Pergunta-se se a verdadeira paixão de Leônia seria o prazer das coisas novas ou o ato de expelir, de afastar de si, de expurgar todos os dias uma impureza sempre recorrente. E o que resulta disso é uma cidade que, renovando-se todos os dias, se conserva integralmente em sua única forma definitiva: a do lixo. Do lixo de ontem "que se junta ao lixo de anteontem e de todos os dias e anos e lustros... (p. 106).

Nossas cidades andam nessa direção. A globalização permite que as grandes 
corporações despejem em nossos terreiros e em nossos monturos os seus dejetos, cujo trabalho de despejo fazemos com nossas próprias mãos. E como essa indústria se alimenta de uma relação libidinal com a novidade, o descarte decorre de duas formas de obsolescência: uma programada, para acelerar o descarte, e que consiste em dotar os produtos de uma existência cada vez mais curta; e outra perceptiva, que diz respeito ao fato de que, a cada coisa nova que se insere no meio social, se instala um novo desespero subjetivo em cada um dos seus membros, que só se cura com o acesso à novidade desejada. Além disso, há também esse desprezo a qualquer ordem mínima de organização da vida, diante mesmo de imperativos existenciais muito comuns e inexoráveis, como decidir o que fazer nossos próprios excrementos. Mas não: "sempre esse significativo abandono que exprime a palavra 'desleixo"” (HOLANDA, op. cit.).

\section{FICUS/NIN}

Saindo de Juazeiro ou de Curaçá e rumando em qualquer direção, você encontrará uma cidade e esta cidade estará arborizada do mesmo jeito. Até bem pouco tempo essa arborização era predominantemente feita com fícus. Fícus (Fícus benjamina L) é uma figueira da família dos Moraceae e da classe dos Angiosperma. Consta que ela é nativa do sudeste asiático, mas há informações na internet de que sua origem é atribuída às regiões tropicais e subtropicais da Linha do Equador, motivo pelo qual a planta se dá bem em climas tropicais e subtropicais, bem como à exposição direta ao sol. Existem cerca de 800 subespécies da planta sendo a mais popular a Fícus benjamina, que já virou praga no Brasil. Porém, recentemente o fícus está sendo substituído, de modo rápido e hegemônico, pelo Nin (Azadirachta indica A. Juss).

Ambientalistas e engenheiros florestais vêm advertindo desde algum tempo para a inadequação de ambas a espécies na arborização urbana ou reflorestamento, especialmente do Nin, que chegou ao Brasil amparado por um mito de "árvore milagrosa", repelente natural etc. Mas, aqui interessa menos o aspecto meramente ambiental ou florestal: interessa mais o aspecto mental em que a arborização predominante com essas espécies está assentada. Não importa, por exemplo, que estejamos no pino do semiárido (como as cidades de Juazeiro e Curaçá), com sol escaldante na maior parte do ano. As árvores plantadas não são para dar sobra ou um pouco mais conforto climático no âmbito das cidades, não é para ajudar no seu arejamento. As árvores são plantadas para serem podadas, do mesmo jeito, no mesmo 
formato, para serem pés de bolinhas verdes. Passando de uma cidade a outra, sendo observador atento e com um pouco de distanciamento crítico, é impossível não se perguntar que tipo de mentalidade coletiva essa imagem expõe. Essa é a questão mais importante: que ecologia de ideias, de ideação (aliás, que ecosofia) subjaz a essa imagem repetitiva. E se vê pouquíssima inciativas de enfrentamento não apenas do plantio, mas da poda. Parece haver um pensamento coletivo no qual "uma árvore existe para ser podada", como se fosse um trabalho de jardinagem. Como disse Guattari (1990), a viagem de uma cidade a outra se converte numa espécie de viagem sem sair do lugar, no seio das mesmas redundâncias de imagens e comportamentos.

Sobre este aspecto da arborização, venho fazendo um conjunto de fotografias dentro um trabalho de registro que chamei de Primavera Urbana, feitas todos os anos por ocasião da primavera, com árvores que dão flor, as cidades - ao contrário do Fícus e do Nin. Essas árvores são raras e, geralmente, nas cidades da região semiárida onde me situo (e se situam as cidades de Curaçá e Juazeiro), ficam restritas ao Ipê Amarelo ou Caraibeira (Tabebuia caraíba), em maior número, e a poucas variações de ipês, como o Ipê Roxo (Tabebuia impetiginosa) e similares. Porém, nesses registros ainda se sobressai no corpo das cidades a arborização raquítica, centrada no Fícus e no Nin, todos dedicados à poda - restringindo o aspecto estético e elevando o espectro de aridez de nossas cidades, ficando evidente a falta de habito das populações para produzir sombra, arejamento e beleza nas nossas experiências urbanas.

\section{Fuleiragem}

O mesmo movimento que você pode fazer saindo de qualquer uma das cidades citadas aqui, em relação aos itens anteriores, você pode também fazer em relação ao tipo de música, de dança, de festa, de diversão, de gesto, que predomina em todas elas. $\mathrm{O}$ formato é mais ou menos o mesmo: a cidade lhe recebe com o lixo the dando boas vindas; a paisagem das ruas e praças rende os seus olhos à aridez das bolotas verdes dos pés de Fícus ou de Nin; e os seus ouvidos têm que se acostumar a um tipo de sonoridade que emana dos sons dos bares - especialmente na "praça principal" da cidade, onde em geral há um ou vários bares equipados com aparelhos de som que levam o nome de paredões, ou são caixas de som ou sons instalados nos porta-malas dos carros... Mas as músicas e o volume com que elas são executadas são sempre os mesmos: em altíssimo volume se executam músicas de um tipo precário de forró, pagode, arrocha, fank ou o 
chamado "sertanejo universitário"... Nem mesmo Juazeiro, que se nomeia "a cidade onde nasceu a Bossa Nova" (há controvérsias, mas João Gilberto é filho de Juazeiro), escapa a esse mapa estético.

As músicas dessa estética sonora são hegemonicamente alinhadas a uma linguagem cada vez mais chula, cuja metáfora do duplo sentido e da picardia foi abolida em benefício da pura literalidade erotizada. Este é um "modo de semiotização dominante". Dispensando os nomes das próprias bandas e dos grupos musicais, as letras, refrões e os nomes das músicas são exemplares disso: "Perereca", "Lapada na Rachada", "Rala a Tcheca no Chão", "Rala a Xana no Asfalto", "Amor de Rapariga", "Um Carro de Raparigas", “Abre as Pernas, Mete a Língua”, “69”, Frango Assado", “Atoladinha”, "Mete Até Gozar", Dá Cachaça a Ela Que Ela Dá”, "Vou te comer, vou te comer", Senta no Meu Pau"...

Não é necessário continuar! Há os que virão dizer, novamente, que aquilo que questiono é a legítima expressão de liberdade das pessoas. Outros virão sugerir que questionar isso é questionar o direito de cada um fazer o que bem quiser da sua vida, e que questionar isso é uma espécie de reação conservadora e moralizante; outros ainda virão afirmar que o questionamento que apresento deixa de ver que "há outras coisas" e que eu estaria operando apenas pelo negativo. A minha questão é se realmente as pessoas têm pelo menos a chance de escolher, se sequer chegam a conhecer outras coisas. Os prefeitos e demais políticos gastam o orçamento que deveria ser destinado às políticas culturais na contratação de bandas deste naipe, alimentando uma indústria do entretenimento especializada em ganhar dinheiro com este tipo de "cultura-mercadoria", quando poderiam estabelecer outros processos de acesso a estéticas e linguagens variadas. As FMs têm se especializado e se restringido a esse tipo de linguagem, reiterando tal "modo de semiotização dominante" que acarreta em sérios problemas nos processos de sociabilidade e subjetivação das novas gerações.

Diante disso não há como não admitir um certo sufocamento da alteridade, como bem sinaliza Guattari (1990, p. 8):

É a relação da subjetividade com sua exterioridade - seja ela social, animal,
vegetal, cósmica - que se encontra assim comprometida numa espécie de
movimento geral de implosão e infantilização regressiva. A alteridade tende a
perder toda aspereza. O turismo, por exemplo, se resume quase sempre a uma
viagem sem sair do lugar, no seio das mesmas redundâncias de imagens e de
comportamento. O que mais me insulta, aliás, é a banalização da ideia de que este "programa 
cultural" presente na maior parte de nossas cidades é pura expressão do povo e de uma "natural" gosto popular, isso dito como se o gosto fosse um atributo inato das pessoas, como se ele já não estivesse vampirizado por todas as indústrias, como se a própria “estética da fuleiragem” já não funcionasse como uma espécie de cera nos ouvidos, a danificar o aparelho auditivo, como a cera que Ulisses dispôs nos ouvidos de seus remadores para poder se deleitar com o refinamento perigoso do canto das sereias (HOMERO, 2003).

\section{Concluindo}

Certamente as reflexões aqui dispostas traem a figura de um flâneur desinteressado. Talvez porque, se as circunstâncias de método nos aproximam, as distinções de contexto nos afastam. Em termos de problematização final, resta algo a dizer sobre os vínculos com a questão das Representações Sociais e dos Discursos. Intuo que os modos de nos representarmos (somos honestos, éticos, ordeiros, comprometidos, limpinhos) são traídos pelas próprias imagens. Há toda uma materialidade que testemunha contra nós. Tomo isso como uma outra representação que nem se vincula ao que nos dizem de nós nem ao que dizemos nós de nós mesmos, mas, decorre do "retrato" do que somos, encarnado na materialidade do corpo das cidades.

Do ponto de vista dos discursos, tendemos a nos indexarmos aos discursos vigentes, a dêixis discursiva (MAINGUENEAU, 1997) expõe isso, não livrando o sujeito da enunciação da indexação ao espírito de bando ou ao efeito manada - e é até difícil encontrar alguém que não declare, por exemplo, que temos que cuidar do meio ambiente e do rio São Francisco, e, por outro lado, o rio continue sendo exaurido por todos, como uma espécie de crime difuso sobre o qual ninguém, individualmente, assume sua parcela de culpa. E as mesmas pessoas que repetem os discursos vigentes sobre o meio ambiente (como um atrelamento a um aparelho social da enunciação), são também as mesmas que poluem e expropriam a coisa pública e a natureza, sem com elas se implicarem ou se comprometerem.

As imagens a que recorri não apenas constituem o real, mas são as minhas chaves para problematizar a incongruência e a inadequação do modo como nos representamos. A minha tese básica vai na direção da palavra-chave que nos ofereceu Holanda (1995) há quase um século: “desleixo”. Em que pese nossa conduta pós- 
moderna (como se fôssemos europeus), parece evidente que não desenvolvemos uma racionalidade básica ou mínima para a gestão de nossas questões coletivas, para melhorar o espectro de nossa vida comum no espaço urbano. E o meio urbano, o meio ambiente, está expondo essa fraqueza, através das imagens da materialidade inerente aos nossos modos de vida.

\section{Referências}

ALBUQUERQUE JR, Durval Muniz de. A invenção do Nordeste e outras artes - São Paulo: Cortez, 1999.

ARENDT, Hannah. A condição humana. - $10^{\mathrm{a}}$ ed. - Rio de Janeiro: Forense Universitária, 2000.

BENJAMIN, Walter. Passagens. - Belo Horizonte: Editora UFMG; São Paulo: Imprensa Oficial do Estado de São Paulo, 2009.

CALVINO, Ítalo. As cidades invisíveis. - São Paulo: Companhia das Letras, 1990.

CHARDIN, Pierre Teilhard de. O fenômeno humano. - São Paulo: Editora Cultrix, 2001.

EUFRASIO, Mário A. Estrutura urbana e ecologia humana: a escola sociológica de Chicago (1915-1940). - São Paulo: Curso de Pós-Graduação em Sociologia da Universidade de São Paulo: Ed. 34, 1999.

FOCAULT, Michel. A Ordem do Discurso. - $5^{\text {a }}$ edição - São Paulo: Edições Loyola, 1999.

GOMES, Roberto. Crítica da razão tupiniquim. - 12a ed. - Curitiba, PR: Criar Edições, 2001.

GONSALVES, Esmeraldo Lopes. Opara: formação histórica e social do Submédio São Francisco - Juazeiro, BA: [s.e], 1997.

GUATTARI, Félix. As três ecologias. Campinas, SP: Papirus, 1990.

HERNÁNDEZ, Fernando. Catadores da cultura visual: transformando fragmentos em nova narrativa educacional. - Porto Alegre: Mediação, 2007.

HOLANDA, Sérgio Buarque de. Raízes do Brasil. - 26a ed. - São Paulo: Companhia das Letras, 1995.

HOMERO. Odisseia. - São Paulo: Martim Claret, 2003. 
KUSKOSKI, Matheus Soares. O animal de rebanho em Nietzsche e o homem de massas em Arendt: paralelos e influências. In: Cadernos de Ética e Filosofia Política, 19, 2/2011, pp.139-155. Disponível online em

$<$ https://www.revistas.usp.br/cefp/article/viewFile/ 55742/59157>. Acessado em

08/08/2017.

MAINGUENEAU, Dominique. Novas tendências em análise do discurso. - $3^{\mathrm{a}}$ ed. Campinas, SP: Pontes: Editora da Universidade Estadual de Campinas, 1997.

MORIN, Edgar. O método IV: as ideias, a sua natureza, vida, habitat e organização. Portugal: Edições Seul: Biblioteca Universitária: publicações Europa-América, 1991.

NIETZSCHE, Friedrich. Além do Bem e do Mal. São Paulo: Companhia das Letras, 2005.

ORTIZ, Renato. Walter Benjamin e Paris - individualidade e trabalho intelectual. In: Tempo Social; Rev. Sociol. USP, S. Paulo, 12(1): 11-28, maio de 2000.

RIBEIRO, Darcy. O povo brasileiro: evolução e o sentido do Brasil - São Paulo: Companhia das Letras, 1995.

RIBEIRO, Wagner Costa. A ordem ambiental internacional. - São Paulo: Contexto, 2001.

SANTOS, Boaventura de Souza. Um discurso sobre as ciências. $-5^{\text {a }}$ edição. - São Paulo: Cortez; 2008.

SÊGA, Rafael Augustus. O conceito de representação social nas obras de Denise Jodolet e Serge Moscovici. In: Anos 90. Porto Alegre, n. 13, julho de 2000. Disponível online em <http://www.ufrgs.br/ppghist/anos90/13/13art8.pdf>. Acesso em 06/08/2017. 